\title{
Load Flow Based Voltage Stability Indices for Voltage Stability and Contingency Analysis for Optimal Location of STATCOM in Distribution Network with Integrated Distributed Generation Unit
}

\author{
Ibrahim Alhamrouni*1, MA Alif², Bazilah Ismail ${ }^{3}$, Mohamed Salem4, \\ Awang Jusoh ${ }^{5}$, T Sutikno ${ }^{6}$ \\ 1,2,3 Department of Electrical, Electronics, University Kuala Lumpur British Malaysian Institute (UniKL BMI), \\ Gombak 53100, Malaysia \\ ${ }^{4}$ School of Electrical and Electronic Engineering, Universiti Sains Malaysia, Engineering Campus, \\ 14300 Nibong Tebal, Pulau Pinang, Malaysia \\ ${ }^{5}$ Faculty of Electrical Engineering, Universiti Teknologi Malaysia, 81300 Skudai, Malaysia \\ ${ }^{6}$ Department of Electrical Engineering, Universitas Ahmad Dahlan, Indonesia \\ *Corresponding author, e-mail: ibrahim.mohamed@unikl.edu.my*1, salemm@usm.my33, \\ awang@fke.utm.my ${ }^{5}$, tole@ee.uad.ac.id ${ }^{6}$
}

\begin{abstract}
Electrical power system is growing rapidly with the current increasing demand. One of many important issues being faced in power system is the voltage instability. With that being said, this work investigates the voltage stability indices with contingency analysis used in order to determine the voltage stability of the network system. These approaches are used to detect and avoid voltage instability in the distribution network. The behavior of the distribution network is determined based on the contingency analysis. STATCOM is injected into selected buses in the distribution network of the system to determine the system's stability during the contingency condition. Distributed generation (DG) is utilized to enhance the network stability. Different scenarios have been assumed in order to test the proposed technique under different conditions. The work has been implemented in Digsilent power factory environment. The proposed technique has been tested on IEEE 30 bus system. Promising results have been obtained with respect to previous published literature, in term of identifying the weak buses and enhancing the overall stability of the network.
\end{abstract}

Keywords: voltage stability indices, distribution network stability, contingency analysis, STATCOM, voltage stability, voltage instability, distributed generation

Copyright $@ 2018$ Universitas Ahmad Dahlan. All rights reserved.

\section{Introduction}

Voltage instability is known to be one of the most common problems occurred in the transmission networks nowadays. This phenomenon occurs when the transmission network reaches its maximum capacity, it can withhold before it breaks down. Due to the increase of demand in electricity especially in the urban regions, it is crucial to have a transmission networks that are capable of exporting large amount of electric power to consumers without producing any problems. Voltage stability is the condition where the power system can sustain steady voltages at all buses in the system after being vulnerable to a disturbance from a given initial operating condition [1]. The voltage stability indices (VSI) are the approaches used in this study to determine the voltage stability in the power system. VSI is a parameters or scalar magnitudes that are actualized to observe the changes of the parameters in the systems. This is one of the easiest and most accurate ways of determining the power system stability nowadays [2]. VSI can be subdivided into two different approaches which are Jacobian matrix based VSI and system variable based VSI [1].

In Jacobian matrix approach, it is less likely to be used in the real power system as it is a very high computational time approach since it calculates the voltage collapse point and the maximum load ability of the system. On the other hand, this approach is less desirable to use for a real-time voltage stability assessment as all the Jacobian matrix changes if there are any 
topological changes in the system leads to the recalculation of the matrix [3, 4]. By using this approach, the increase amount of computational time can cause the problem of determining the optimal location of the wind farm as well as satisfying the power system constraints [5]. On the contrary, the system variable based VSI approach is more suitable to be used in the system as it requires less computational time compared to the Jacobian matrix based VSI method and it provides sufficient information required in order to verify the voltage stability of the system. This approach is also suitable to be used in real-time applications.

Contingency analysis method is also conducted in line together with the voltage stability analysis in this study in order to determine the voltage stability of the power system. This method is done by developing a new algorithm that can analyse and rank the contingencies automatically thus minimizing the computation time and human error [3]. In contingency analysis, transmission line outage and ranking processes are accomplished in order to determine the overloads in transmission lines and to determine the bus voltages that already exceeded their voltage limit [3]. In this method, by referring to the parameters obtained in the contingency analysis, selected transmission line which is suspected to be a weak transmission line is removed from the power system [7]. The power system is then reanalysed after the suspected transmission line is removed to determine the voltage stability of the power system as well as to make sure all power system constraints are satisfied [8]. They are few ways of approaching parameters in determining the voltage stability of the power system [9].

Once all the parameters are obtained, the optimal location of the STATCOM will be determined. By integrating DG and STATCOM in the distribution system, it can result in more reliability power system apart from improving the voltage profile of the system and reduce the costs and losses. It is crucial to get the accurate calculations and parameters to determine the optimal location of the DG and STATCOM in order to prevent power degradation and unreliable power system $[10,11]$. In this system, wind power plant is used and integrated into the weakest bus in the system. Thus the difference in the behaviour of the system will be determined based on different scenarios. Connecting DG to the weak buses to ensure the reliability of the power system to increase and to ensure the voltage stability of the system is maintained. By having a distributed generation in the distribution system, it can reduce power losses in the system and also improve the power quality of the distribution network [12,13]. However in this study, the power quality improvement will be made alsoby connecting STATCOM into the power system [14]. Few different potential locations are selected in this study to determine the optimal location of STATCOM integration into the power system. Thus by comparing the voltage stability indices during the STATCOM injection to the selected buses, the optimal location of STATCOM will be chosen based on the overall improvement of the power system in terms of its voltage stability.

\section{Proposed Techniques}

This work tests the network in different conditions to ensure that, the system maintains its equilibrium status. The conditions are as follows:

\subsection{Base Case Condition for IEEE 30 Bus Test System}

The single line diagram of IEEE 30 bus test system is as shown in the Figure 1, where the wind power plant will be installed at Bus 26. This benchmark system consists of 30 buses, 21 loads, 6 generators including slack generator, 7 transformers, 2 shunt capacitor and 41 transmission and distribution lines with four different voltage levels. Power flow analysis is done by using Newton-Rhapson to ensure the validity of this system by making sure the system is converged during the simulation and the voltage characteristics of each bus remain within the value of $1 \mathrm{pu}[15]$.

\subsection{Maximum Loadability Limit Test of IEEE 30 Bus Test System}

Maximum load ability limit test will be done to the IEEE 30 bus test system in order to determine the strength of all the buses in the network system. This test is done by increasing the reactive power in each bus in the distribution network until it reaches its threshold value. Once the reactive power exceeds the value the bus can withhold, the system will become unstable and collapsed. The buses selected in this test will be categorized into two categoriesweak buses and intermediate buses. Three weak buses will be selected in which the bus could 
withhold small amount of reactive power injection, and two intermediate buses will be selected near the weak buses. Intermediate buses are the buses that are neither a weak bus nor a strong bus, where the buses can withhold higher value of reactive power injection than weak buses but not more than the strong bus and the location selected for intermediate buses are the buses that located near the weak buses in the network system [16].

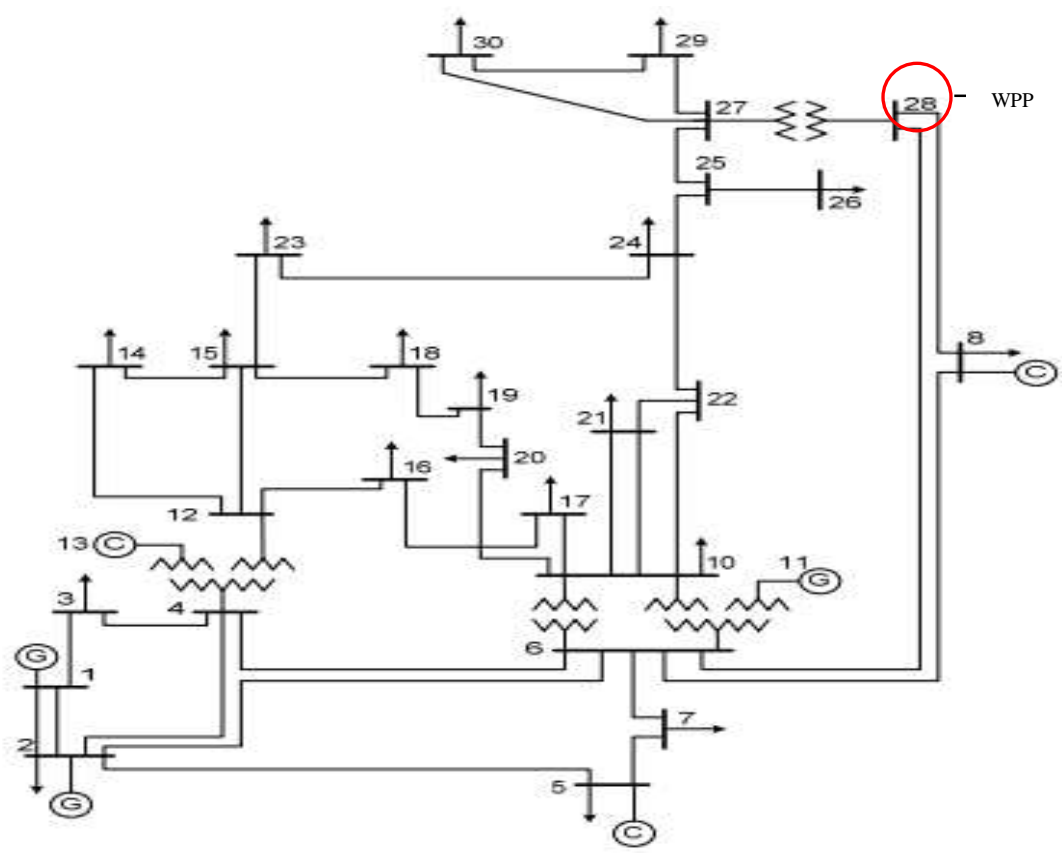

Figure 1. Single line diagram of IEEE 30 bus test system with integrated wind farm [13]

\subsection{Voltage Stability Indices with Contingency Analysis}

Method used to determine the voltage stability indices (VSI) is by using the system variables method. This method is used because of its suitability of this method to determine the VSI in terms of the computational time and is adequate for real-time applications. Three different approaches of VSI will be used in this study with contingency analysis [17].

\subsubsection{Line Stability Index}

$$
L_{m n}=\frac{4 X Q_{r}}{\left(V_{i} \sin (\theta-\delta)\right)^{2}}
$$

Where; $\mathrm{X}$ is the reactance

$\theta$ is the line impedance angle

Qr is the reactive power at the receiving end

$\mathrm{Vi}$ is the voltage at the sending end

$\delta$ is the phase angle at the buses

\subsubsection{Line Stability Factor (LQP)}

$$
L Q P=4\left(\frac{X}{V_{i}^{2}}\right)\left(\frac{X}{V_{i}^{2}} P_{i}^{2}+Q_{r}\right)
$$

where; $X$ is the reactance of the line

$\mathrm{Vi}$ is the nominal voltage at the bus

$\mathrm{Pi}$ is the active power at the sending end

Qr is the reactive power at the receiving end 


\subsubsection{Fast Voltage Stability Index}

$$
\mathrm{FVSI}=\frac{4 \mathrm{Z}^{2} \mathrm{Q}_{\mathrm{r}}}{\mathrm{V}_{\mathrm{i}}^{2} \mathrm{X}}
$$

where; $Z$ is the line impedance

$X$ is the line reactance

Qr is the reactive power at the receiving end

$\mathrm{Vi}$ is the voltage at the sending end

All these three approaches will be used to calculate voltage stability of the system with contingency analysis. The comparison between three different approaches of VSI will be used in order to determine the behaviour of each potential bus in the system. Two different tests will be conducted where the weakest line and the strongest in the system will be disconnected from the system and tested to determine the voltage stability of the system. The weakest line in the network system will be removed temporarily and the behaviour of the network system will be analysed. Consequently, the strong line in the network system is removed temporarily after the weak line is reconnected to the system and the overall performance of the system is analysed [18], [19].

\subsection{Optimal Location of STATCOM Injection in the Distribution Network}

Several case studies will be conducted to analyse the possible placement of STATCOM in the distribution network that will enhanced the voltage stability performance of IEEE 30 bus system as follow:

a. Case 1

Injecting STATCOM to three selected weak buses in the network system under contingency condition when weak line is removed from the system.

b. Case 2

Injecting STATCOM to two different potential intermediate buses closed to the weak bus under contingency condition when weak line is removed from the system.

c. Case 3

Injecting STATCOM to two different potential intermediate buses closed to the weak bus under contingency condition when weak line is removed from the system.

d. Case 4

Injecting STATCOM to two different potential intermediate buses closed to the weak bus under contingency condition when strong line is removed from the system. In this scenario, the VSI used to determine the voltage stability of the system will be FVSI method. All the FVSI value will be calculated and measured based on the parameters obtained during each of the case study proposed. The lowest FVSI value will be selected as the optimal location of STATCOM integration to the network system with DG unit. Figure 2 shows flow chart of the proposed technique.

\section{Results}

The normal condition of the IEEE 30 bus test system designed based on the parameters are used and tested with different type of conditions. The voltage stability indices, maximum load ability limit for all buses connected to $33 \mathrm{kV}$ transmission line obtained from the previous chapter are used to determine the weak bus, intermediate and strong buses in the network system. By using contingency analysis under two different circumstances, the voltage stability indices are recalculated to observe the changes occurred in the system during contingency condition. STATCOM is implemented in the potential buses in this case, a few selected weak buses and intermediate buses and the optimal location of the STATCOM will be determined based on the improvement of VSI of the 30 bus test system. The most improvement made in terms of the overall performance of the network system with the integrated STATCOM will be the optimal location of the STATCOM.

\subsection{Voltage Characteristics of Base Case Condition}

Base case condition is the normal condition of the IEEE 30 bus test system designed based on the parameters given. To ensure the validity of the network system, the voltage 
characteristics of each bus in the base case condition must remain near the value of $1 \mathrm{pu}$. From Figure 3, the voltage characteristics of each bus are determined and the value obtained on each bus remained near the value of $1 \mathrm{pu}$, ergo the system is working perfectly in stable manner. After validating the working condition of the system, the tests can be done to the system to examine the voltage stability of the system.

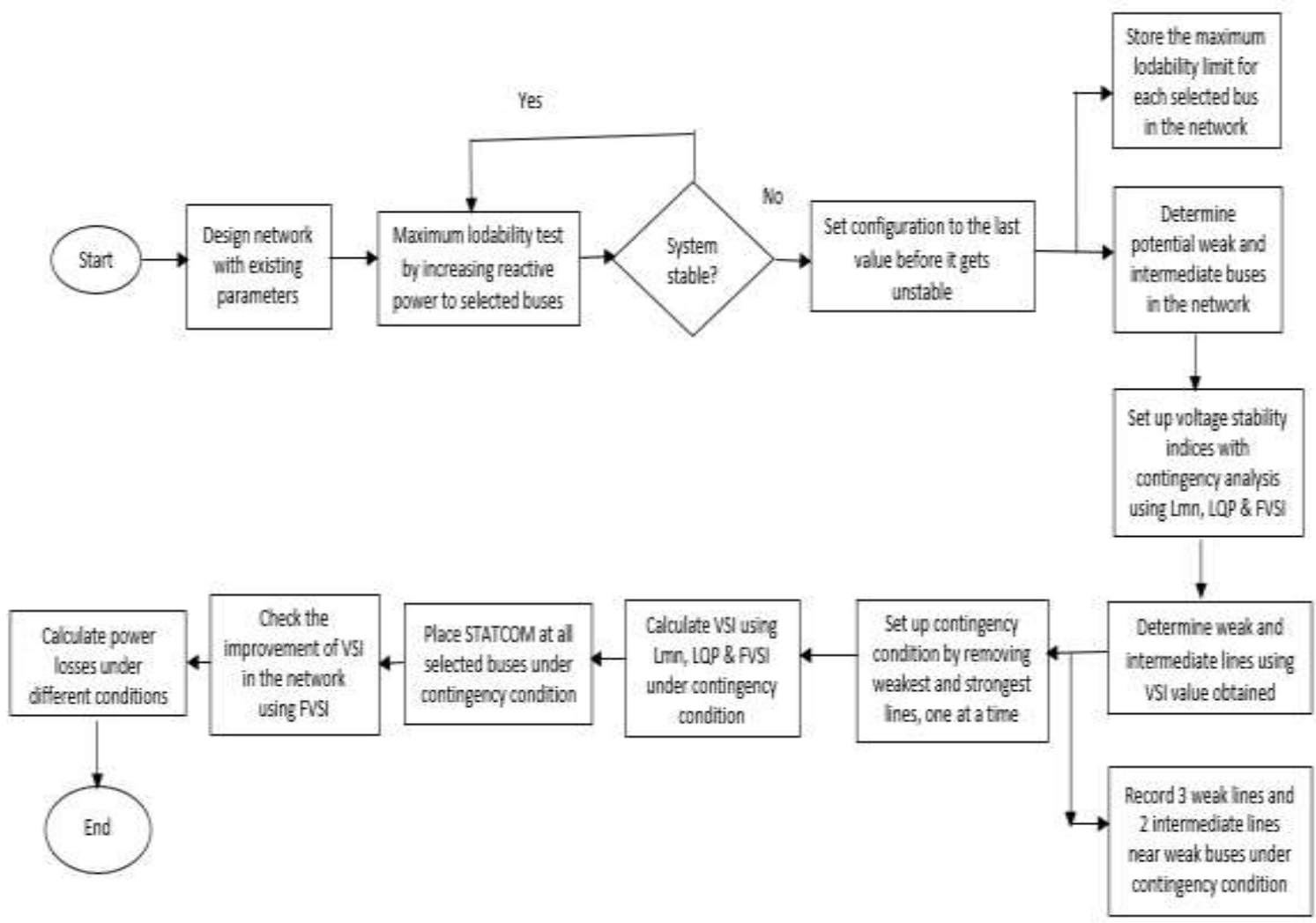

Figure 2. Flow chart of the proposed technique

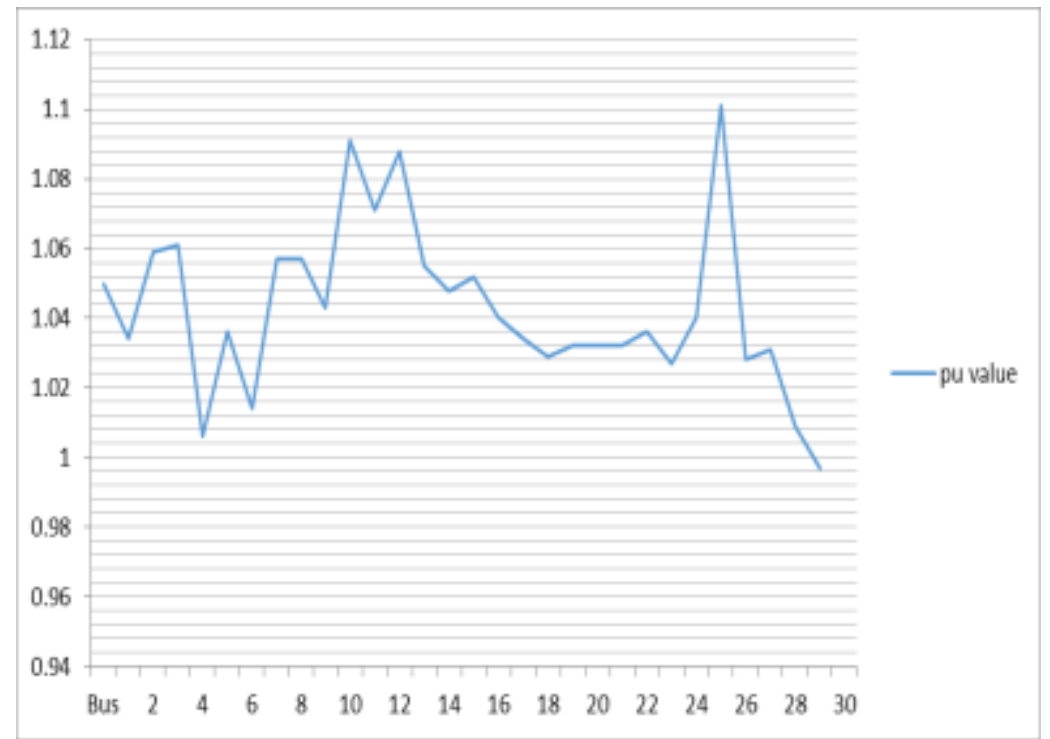

Figure 3. Voltage characteristics of each bus in the IEEE 30 bus test system 


\subsection{Maximum Loadability Limit Test Results}

Each bus will be tested to determine the maximum load ability it can withstand before the stable condition collapsed and become unstable. This is done by testing each selected bus manually. Reactive power is injected into each selected bus manually until the system collapsed and unstable.

From Figure 4, three weak buses are selected and two intermediate buses are selected. The buses are selected based on the value of reactive power it can withhold in this case, the less reactive power it can withhold the weaker the bus is and vice versa. Table of listed weak buses and intermediate buses selected based on the graph is shown in Figure 4.

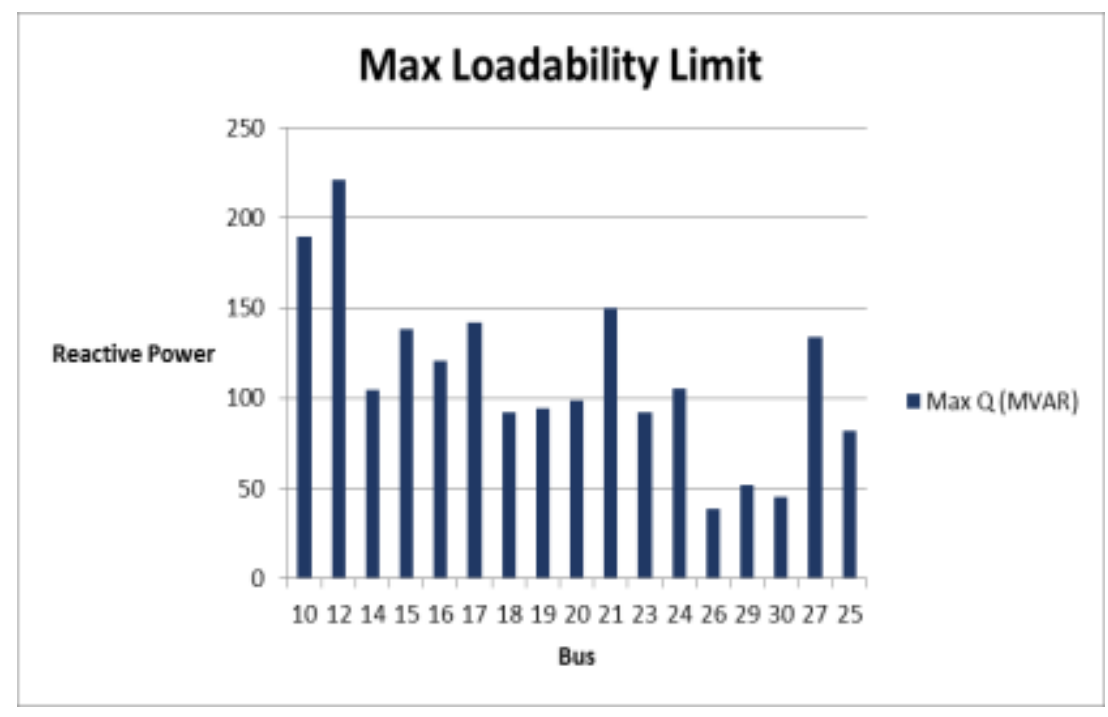

Figure 4. Maximum loadability limit for buses in the distribution network

From Table 1, bus 26 recorded the lowest reactive power it can with hold with 38.8MVAR only thus categorised as the weakest bus in the system. The intermediate buses selected are bus 27, bus 25 and bus 17 that will be used in the case study later in this thesis. Considering the distance between the location of the bus and the point of transmission and distribution, it can be estimated that the condition of the buses falls into different categories. the buses will become weaker as the distance between the buses to the point of transmission and distribution increased. Consequently, stronger buses will be located near the point of transmission and distribution

\begin{tabular}{ccc} 
Table 1. Maximum Loadability & Limit of Selected B \\
\hline \multirow{2}{*}{ Bus category } & Buses & Maximum Q (MVAR) \\
\hline \multirow{2}{*}{ Weak } & 26 & 38.8 \\
& 30 & 45.4 \\
\multirow{2}{*}{ Intermediate } & 29 & 51.6 \\
& 27 & 134 \\
& 25 & 81.6 \\
\hline
\end{tabular}

\subsection{VSI for Base Case Condition of IEEE 30 Bus Test System}

Three different types of VSI are used in this thesis to determine the behaviour of the system. The line stability index, line stability factor and fast voltage stability index of voltage stability indices are selected to be used in this thesis to calculate the voltage stability of the system. These values are compared in the same manner for the base case condition to see the different approaches results. All the method of VSI used in this study are tabulated together in order to see the difference between the value achieved by different method used under the base condition of the system. 
Based on the value obtained in the Table 2, the weakest line in the system is line 29 to line 30 followed by line 25 to 26 and line 27 to 30 . Thus the weakest line will be used in the contingency analysis to analyse the behaviour of the system. For the intermediate line, line 23 to 24 is selected as the intermediate line near the weak bus. Both of these lines will be used in contingency analysis study by disconnecting one line at a time and the VSI will be recalculated. Figure 5 shows comparison between three different VSI approaches on base case condition.

Table 2. Selected Weak Lines and Intermediate Lines under Base Case Condition

\begin{tabular}{cc}
\hline Line category & Lines \\
\hline \multirow{3}{*}{ Weak } & Line 29 to 30 \\
& Line 25 to 26 \\
Line 27 to 30 \\
Intermediate & Line 23 to 24 \\
& Line 24 to 25 \\
\hline
\end{tabular}

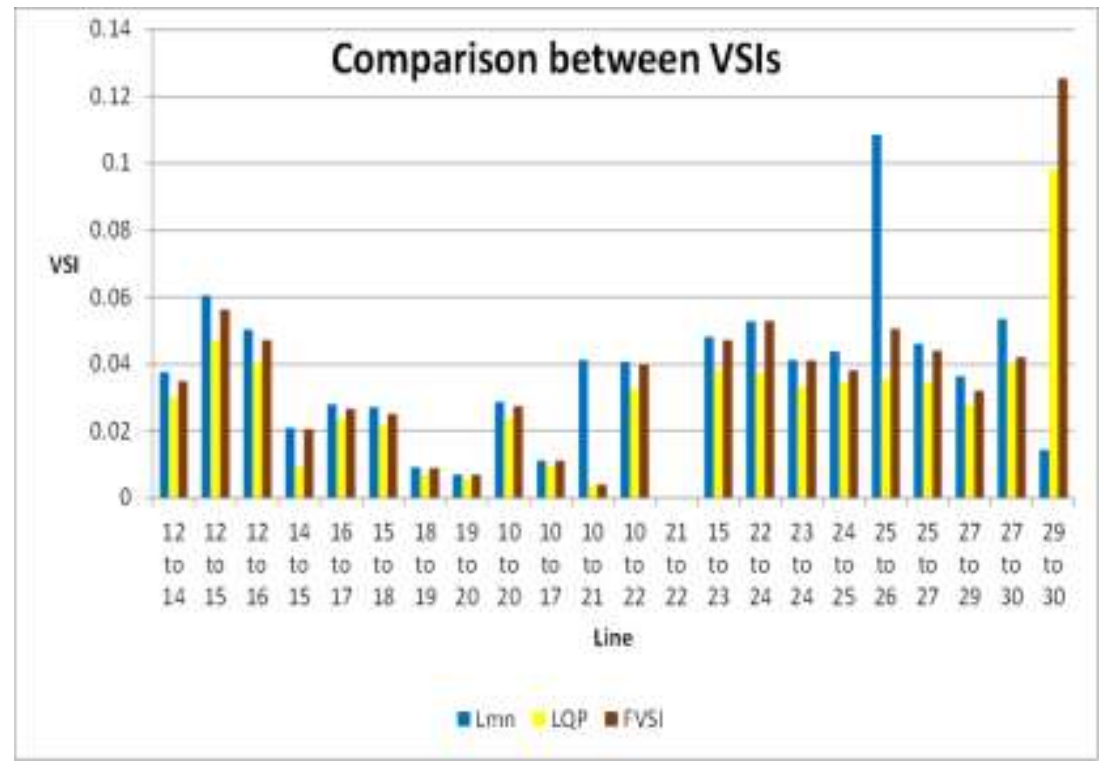

Figure 5. Comparison between three different VSI approaches on base case condition

\subsection{VSI for Base Case Condition of IEEE 30 Bus Test System}

The VSI with contingency analysis is calculated to determine the weakest line in the 30 bus test system. By implementing contingency analysis, one line will be disconnected from the system to identify the changes in the overall performance of the 30 bus test system. The contingency analysis will be done to the most potential weak line in the bus test system and the VSI will be determined. The second contingency condition is also tested by removing the strongest line in the system and the VSI will also be determined. The overall performance of the system is examined based on both contingency conditions.

\subsubsection{Contingency Analysis by Disconnecting Weak Line}

The difference between each VSI method used can be seen by the output value of each method used. The graph is also illustrated to show the difference between the VSI approaches. Each line has their own VSI value and different VSI approach used resulted in different values. The illustration of the difference in the value obtained is shown in the Figure 6.

From Figure 6, two different categories are selected which are weak category and intermediate category. Weak category is the category where the line has the most potential of being unstable and collapsed in the system during this condition. Thus line 27 to 29 indicated the highest possibility to become unstable in the system due to the fact that the line has the highest value of VSI calculated in this condition. Three lines are selected as the weak lines in 
this scenario as they recorded the highest value of VSI compared to other lines in the network system which is line 27 to 29 , line 25 to 26 and line 27 to 30 .

In this scenario, the intermediate lines selected are not the weak or strong line located near the weak buses. Ergo, line 23 to line 24 indicated the best intermediate line in this condition. Another intermediate line selected is line 24 to line 25 which is also located near the weak buses in the network system.

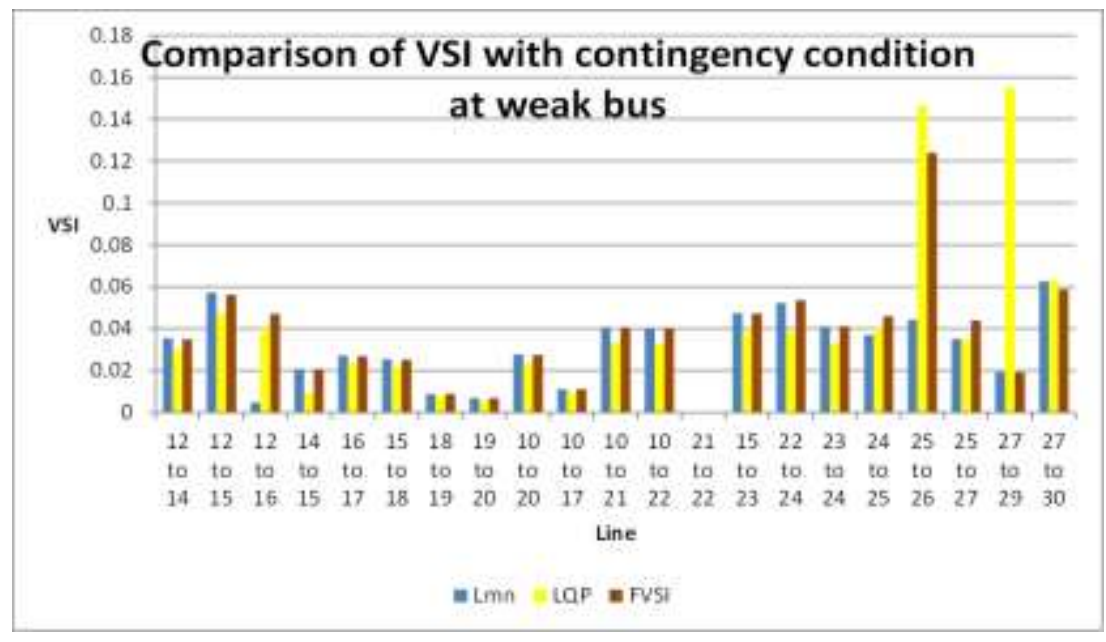

Figure 6. Comparison between three different VSI approaches on contingency condition at weak bus

\subsubsection{Contingency Analysis by Disconnecting Strong Line}

The selected line will be disconnected from the system without changing any of the connected system. In this section, strong line selected will be disconnected from the system and the output of the simulation is recorded. The strongest line recorded in this system in this study is line 23 to 24 . Thus removing this line from the network system will be simulated and the VSI calculations on all approaches proposed will be done. Figure 7 shows comparison between three different VSI approaches on contingency condition at strong bus.

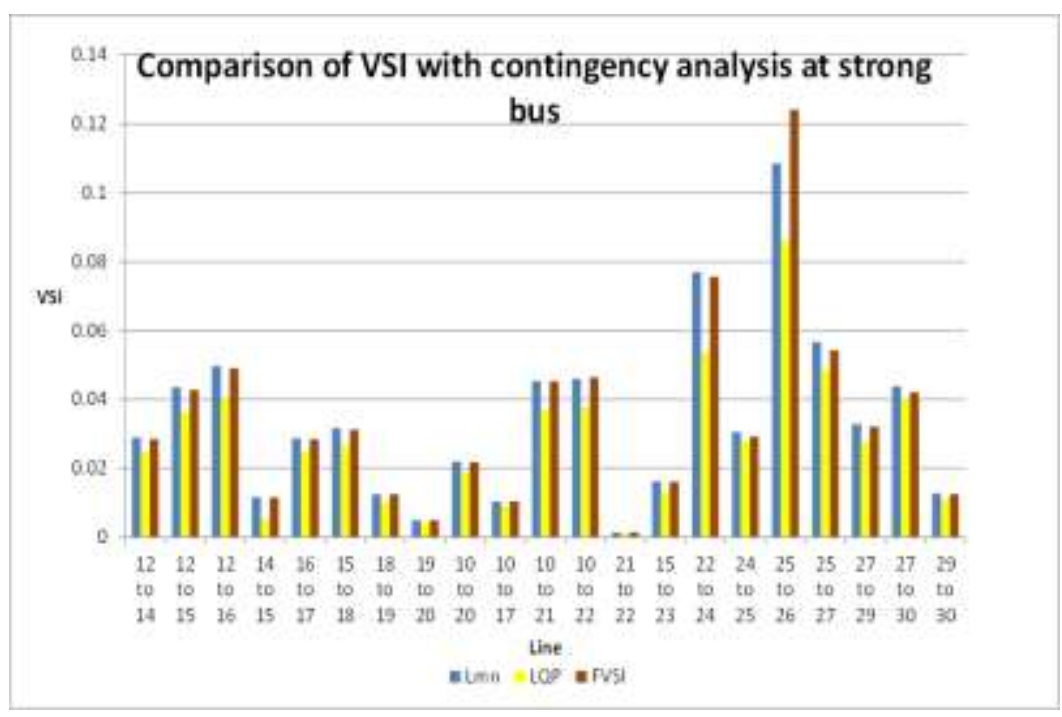

Figure 7. Comparison between three different VSI approaches on contingency condition at strong bus 
The difference in FVSI can be seen from the FVSI obtained in both conditions. Higher value of FVSI is recorded when strong line is removed from the network system compared to the weak line. Based on previous study of [3], this is supporting evidence that removing weak line from the system increase the overall performance of the network system. Thus by comparing contingency analysis of weak line and strong line in the network system, the FVSI obtained for both conditions are diferent, where removing weak line from the system improve the voltage stability of the network system more than removing strong line from the network system.

\subsection{Optimal Allocation of STATCOM in the IEEE 30 Bus Test System}

In this case, three different weak buses and two intermediate buses are selected based on the maximum loadability test done in case B of this paper. These buses are injected with STATCOM and the behavior of the system is observed. To determine the optimal location of the STATCOM, the improvement of VSI in all the buses are observed and the in this case study, two different conditions are held which is the disconnection of weak line 29 to 30 , and the strongest line in the system of line 23 to 24 . The VSI of the transmission lines in the system are recorded.

\subsubsection{STATCOM Injected During Contingency Analysis at Weak Line}

During this case, the weak line 29 to 30 is disconnected from the system thus creating contingency condition. During this condition, the injection of STATCOM is made at selected buses and the performance of the system is observed.

Based on the results obtained from Figure 8, it can be observed that during contingency condition of weak line, the optimal location of STATCOM injection is at bus 26 . Thus the best location to inject STATCOM in the IEEE 30 bus test system is at the weakest bus. It can be observed that the best enhancement in the system occurred when the STATCOM is injected in bus 26 thus proving that injection of STATCOM at the same bus as the DG unit resulted with the best improvement on the system. In this section, the optimal allocation of STATCOM to the distribution network is at the weakest bus where the DG unit is injected.

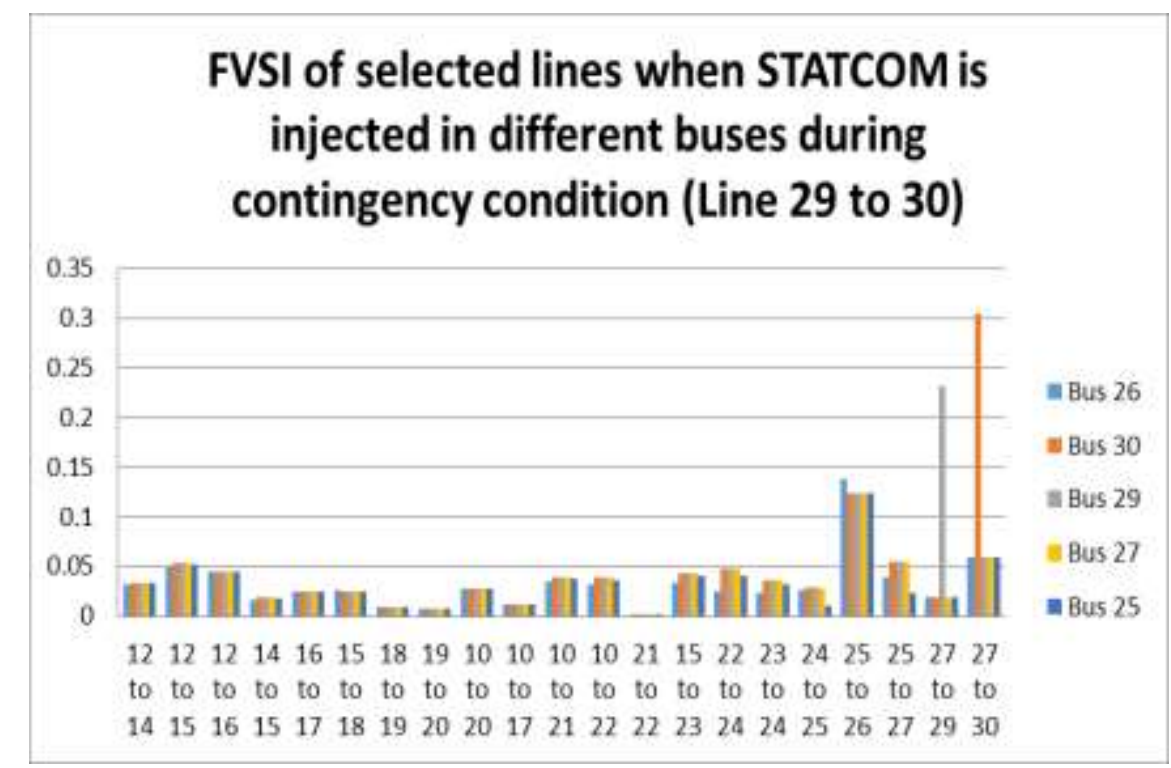

Figure 8. FVSI of selected lines when STATCOM is injected in different bus during contingency analysis of strong line

\subsubsection{STATCOM Injection during Contingency Analysis at Strong Line}

Strong line 23 to 24 is disconnected from the system thus creating contingency condition in the network system. During this condition, the injection of STATCOM is made at 
selected buses and the performance of the system is observed. All the data obtained based on the calculation of FVSI in different location of STATCOM injection is tabulated in table 45. These values are compared to determine the optimal location of the STATCOM injection to the network system. The value of FVSI indicated the strength of each line in connected to the buses in the network system. The smaller the value of FVSI obtained, the stronger the lines are in the network system.

The value of FVSI obtained is higher compared to the value of FVSI obtained when the weak line is removed from the network system. Thus it can be proven that when the strong line is disconnected or removed from the system, the voltage stability of the system is decreased thus having the higher possibility to breakdown or collapsed compared to the disconnection of the weak line. In this study case, the best improvement made to the network system is when the STATCOM is injected to weakest bus 26 . The value of FVSI obtained from bus 25 is slightly lower at the weak line 25 to 26 . However, in terms of the overall performance of the network system is the best to all the selected lines in this case study when the STATCOM is injected to bus 26 . This is by also comparing the FVSI value obtained in all the lines selected in this case study. Only small difference can be observed from the STATCOM injection of bus 25 to 26 thus proving that bus 26 is the weakest bus in the system. In this scenario, it can be concluded that by injecting STATCOM to the network system at the weak bus improved the voltage stability of the network system the most compared to injecting STATCOM to other buses in the network system. Figure 9 shows FVSI of selected lines when STATCOM is injected in different bus during contingency analysis of strong line.

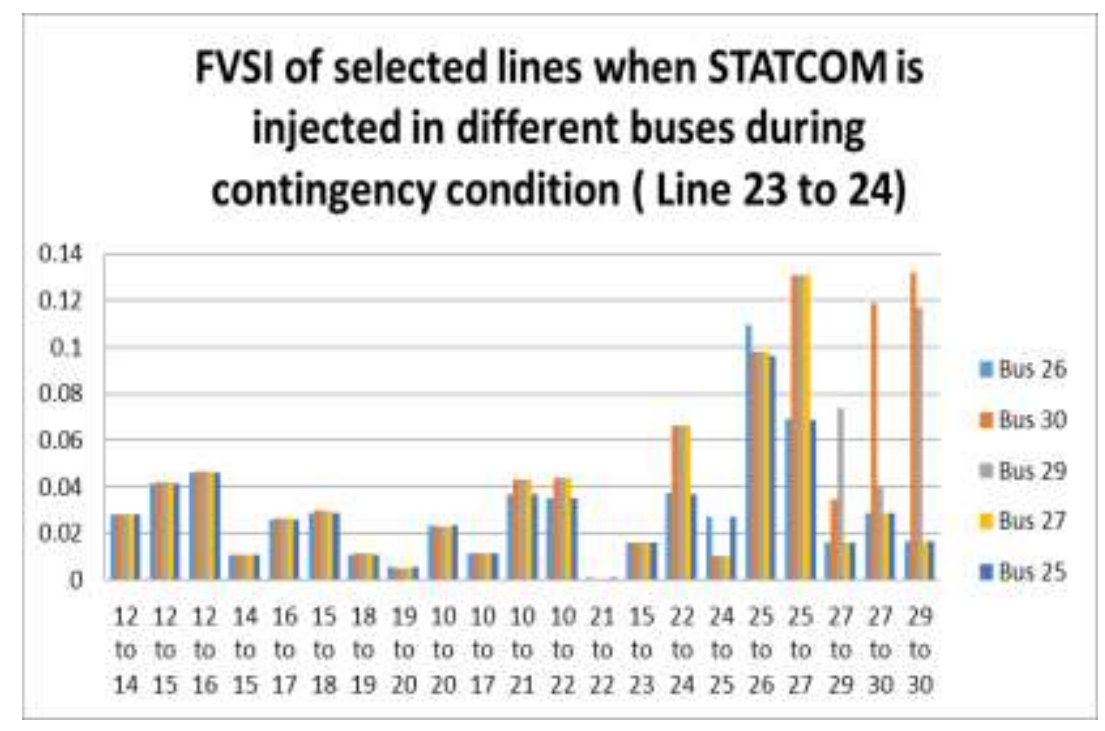

Figure 9. FVSI of selected lines when STATCOM is injected in different bus during contingency analysis of strong line

\subsection{Power Losses of the Network System in Different Bus Location of STATCOM Integration during Contingency Analysis}

In this scenario, different locations of the STATCOM are injected to the network system to determine the different in the power losses under the different location. Five different locations are selected based on the strength of the buses. The buses selected are weak buses 26,30 and 29 with two intermediate buses 27 and 25. To determine the best location of STATCOM penetration into the network system, the power losses in the overall network system is observed.

\subsubsection{STATCOM Injection during Contingency Condition at Weak Line}

In this condition, weak line 29 to 30 is removed temporarily from the network system to determine the system's behavior and changes. When the weak line is removed, STATCOM is 
injected in the selected buses to determine the power losses between injecting STATCOM to different buses with the base case condition of the network system. The results of the simulation are recorded and tabulated into the Table 3.

Table 3. Power Losses Calculated based on Different Location of STATCOM Injection during Contingency Condition at Weak Line

\begin{tabular}{cccc}
\hline Bus & $\mathrm{P}(\mathrm{MW})$ & $\mathrm{Q}(\mathrm{MW})$ & $\mathrm{S}(\mathrm{MW})$ \\
\hline No STATCOM & 14.76 & 46.09 & 48.4 \\
26 & 14.66 & 33.79 & 36.83 \\
30 & 15.04 & 34.61 & 37.74 \\
29 & 15.04 & 34.61 & 37.74 \\
27 & 14.79 & 34.1 & 37.17 \\
25 & 14.64 & 33.89 & 36.91 \\
\hline
\end{tabular}

From Figure 10, the value of power losses in terms of its apparent power is the lowest when the STATCOM is injected in the weakest bus, which is bus 26 . The total amount of power losses calculated is 36.83 MVA. Thus by comparing the amount of power losses in all the selected buses, it can be concluded that the STATCOM that is injected in the weakest bus, bus 26 enhanced the overall performance of the system during this contingency condition.

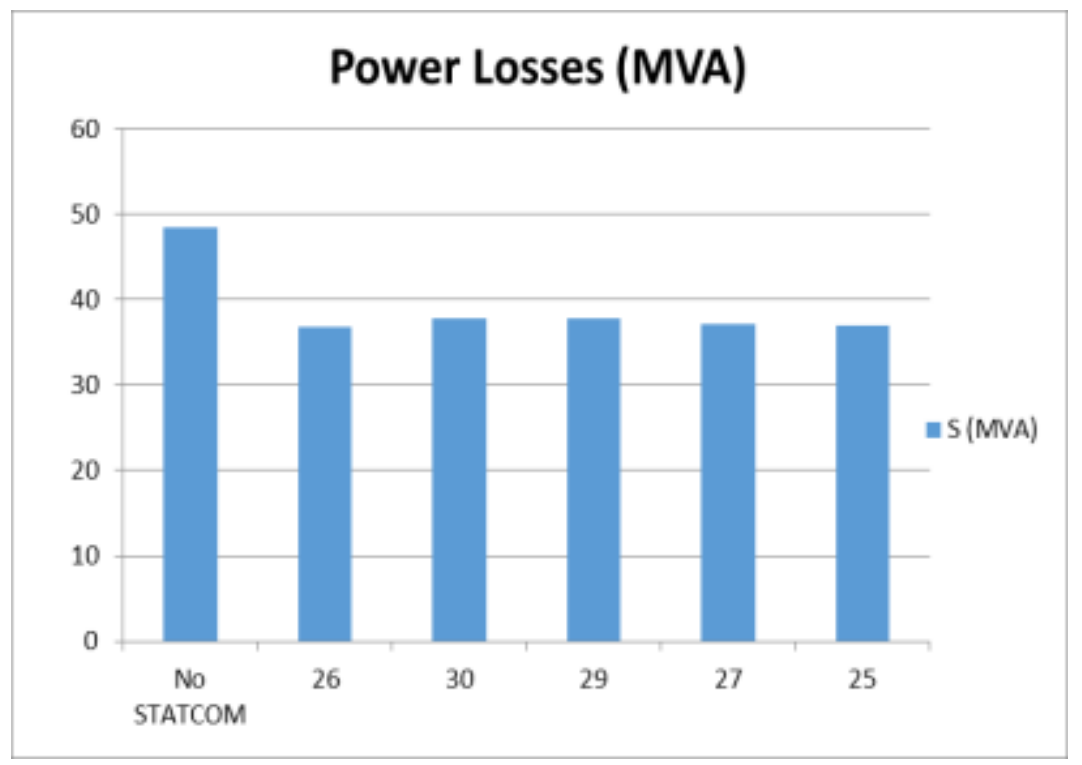

Figure 10. Power losses of the overall network system based on the location of STATCOM injection during contingency analysis at weak line

\subsubsection{STATCOM Injection during Contingency Condition at Strong Line}

In this condition, strong line 23 to 24 is temporarily disconnected from the network system to determine the changes in the overall performance of the network system. Five different locations of STATCOM is injected in the system during this scenario including the base case condition where no STATCOM is injected at all to the network system. Table 4 shows power losses calculated based on different location of statcom injection during contingency analysis at strong line.

From Figure 11, the lowest amount of power losses resulted from the simulation based on the conditions is bus 26. When STATCOM is not injected at all in the system, the system recorded the highest amount of power losses in the system which is 48.4 MVA thus proving that injection of STATCOM to the system improves the performance of the network system. To indicate the optimal location of STATCOM injection to the network system, the lowest amount of 
power losses recorded when STATCOM is injected will be chosen ergo bus 26 will be chosen as the optimal location during this contingency condition. Thus, based on supporting evidence from previous study [17], the best optimal location for the STATCOM penetration to enhance the performance of the network system is at the PCC where the bus is also injected with distributed generation unit.

Table 4. Power Losses Calculated based on different location of STATCOM Injection during Contingency Analysis at Strong Line

\begin{tabular}{cccc}
\hline Bus & $\mathrm{P}(\mathrm{MW})$ & $\mathrm{Q}(\mathrm{MW})$ & $\mathrm{S}(\mathrm{MW})$ \\
\hline No STATCOM & 14.76 & 46.09 & 48.4 \\
26 & 14.52 & 33.49 & 36.50 \\
30 & 14.80 & 34.11 & 37.18 \\
29 & 14.79 & 34.09 & 37.16 \\
27 & 14.66 & 33.82 & 36.86 \\
25 & 14.55 & 33.50 & 36.52 \\
\hline
\end{tabular}

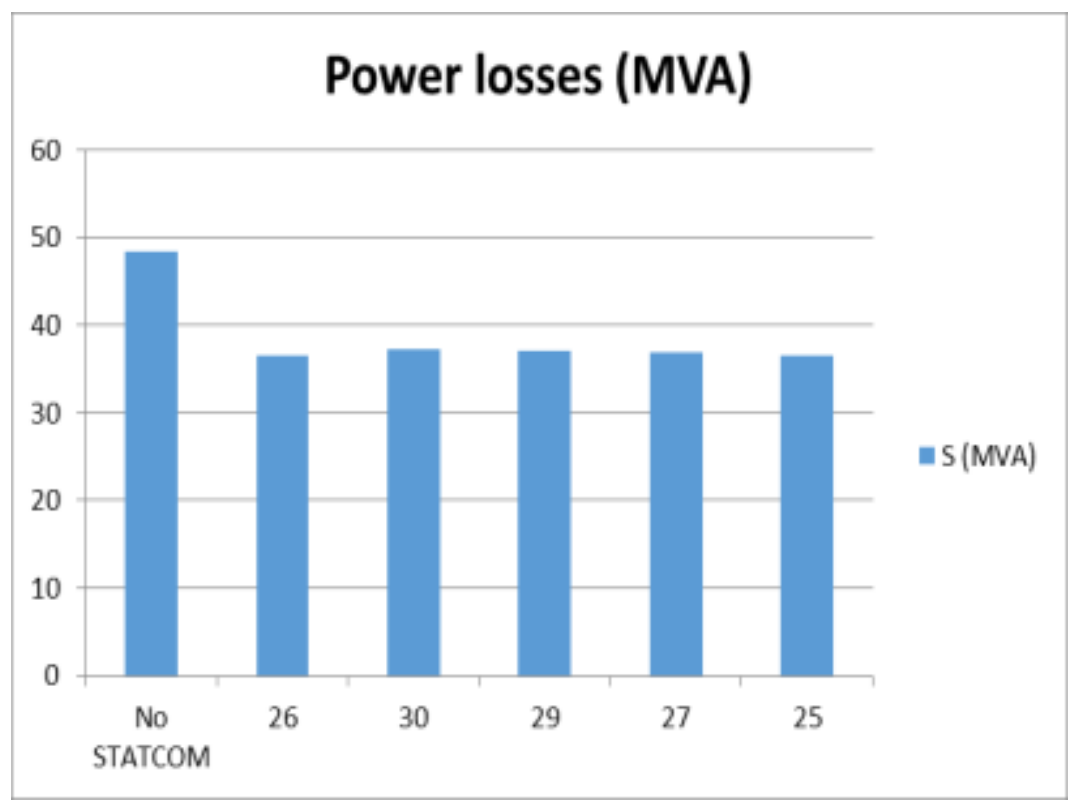

Figure 11. Power losses of the overall network system based on the location of STATCOM injection during contingency analysis at strong line

\section{Discussions}

In this thesis, the base case condition of the IEEE 30 bus test system is designed based on the existing parameters given. During the maximum loadability limit test, the manual testing of determining the maximum reactive load each selected bus could turned out to have a large amount of error due to the fact the number is manually configured. In study case 3, different locations of STATCOM are injected to the network system based on two different conditions. When the weak line is removed the STATCOM is injected and the overall performance of the network system is analyzed. Similarly, same procedures are done in determining the optimal location of STATCOM by removing the strong line in the network system. The design of the IEEE 30 bus test system under different circumstances is a success based on the supporting evidence of previous studies. Power losses for both contingency conditions where weak line and strong line are removed from the network system shows that the injection of STATCOM to the weak bus in the network system improves the overall performance in terms of the power losses in the system. The improvement of the overall performance can also be concluded in terms of voltage stability of the power system based on the voltage stability indices approach used in this thesis. 


\section{Conclusion}

In this study, the implementation of voltage stability indices with contingency analysis is used to determine the voltage stability in the network system by using IEEE 30 bus test system with wind farm integration. Using the powerful simulation software, DigSilent PowerFactory Simulation the implementation of the single line diagram of IEEE 30 bus test system and the integration of STATCOM into the network system is performed to improve the overall performance of the network system. This procedure is done under the contingency conditions which can be divided into two, weak line contingency analysis and strong line contingency analysis. When the weak line is removed from the system, the system is tested with the injection of STATCOM to observe the difference in the performance of the system. Similarly, strong line is removed in the system and the same procedure is done to determine the performance in terms of the stability of the network system. The optimal location of the STATCOM is investigated in this work under different conditions. Four different study cases are also classified in this research to investigate the performance of the network system under different conditions and situations.

\section{References}

[1] Goh HH, Chua QS, Lee SW, Kok BC, Goh KC, Teo KT. Comparative study of line voltage stability indices for voltage collapse forecasting In Power Transmission System. Universiti Tun Hussein Onn Malaysia (UTHM); 2015.

[2] Qu S, Wang Z, Zhang Q, Zuo J, Sun Y, Wu D. Voltage stability analysis for load center with distributed generation. In 2016 IEEE Advanced Information Management, Communicates, Electronic and Automation Control Conference (IMCEC), . 2016: 850-853.

[3] Modarresi J, Gholipour E, Khodabakhshian A. A comprehensive review of the voltage stability indices. Renewable and Sustainable Energy Reviews. 2016; 63: 1-2.

[4] Ravindra S, Reddy VV, Sivanagaraju S. Power system security analysis under transmission line outage condition. Power. 2015; 3(1).

[5] I Alhamrouni, AB Khairuddin, AK Ferdavani, M Salem, A Alnajjar. Differential evolution algorithm for multistage transmission expansion planning based on AC load flow model. 3rd IET International Conference on Clean Energy and Technology (CEAT) 2014, Kuching. 2014: 1-4.

[6] Alhamrouni I, Khairuddin AB, Salem M, Ismail B. Analytical hierarchy process for scheduling the priorities of the environmental factors in transmission lines maintenance. In 2015 IEEE Conference on Energy Conversion (CENCON). 2015: 436-441.

[7] Musirin I, Rahman TA. Fast automatic contingency analysis and ranking technique for power system security assessment. In Proceedings Student Conference on Research and Development, 2003. SCORED 2003. 2003: 231-236.

[8] Alhamrouni I, Khairuddin A, Ferdavani AK, Salem M. Transmission expansion planning using ACbased differential evolution algorithm. IET Generation, Transmission \& Distribution. 2014; 8(10): 1637-44.

[9] Prakash R, Sujatha BC. Optimal placement and sizing of DG for power loss minimization and VSI improvement using bat algorithm. In 2016 National Power Systems Conference (NPSC). 2016: 1-6.

[10] Sun Z, Li W, Zhu J, Liu Q, Liu T. A planning method for siting and sizing of distributed generation based on chance-constrained programming. In 2015 5th International Conference on Electric Utility Deregulation and Restructuring and Power Technologies (DRPT). 2015: 527-531.

[11] Chen H, Chen J, Shi D, Duan X. Power flow study and voltage stability analysis for distribution systems with distributed generation. In 2006 conference IEEE Power Engineering Society General Meeting. 2006: 8-pp.

[12] Qu S, Wang Z, Zhang Q, Zuo J, Sun Y, Wu D. Voltage stability analysis for load center with distributed generation. In Advanced Information Management, Communicates, Electronic and Automation Control Conference (IMCEC), 2016 IEEE. 2016: 850-853.

[13] Rath A, Ghatak SR, Goyal P. Optimal allocation of distributed generation (DGs) and static VAR compensator (SVC) in a power system using Revamp Voltage Stability Indicator. In 2016 National Power Systems Conference (NPSC). 2016: 1-6.

[14] Mishra VJ, Khardenvis MD. Contingency analysis of power system. In 2012 IEEE Students' Conference on Electrical, Electronics and Computer Science (SCEECS). 2012: 1-4.

[15] Ghahremani E, Kamwa I. Optimal allocation of STATCOM with energy storage to improve power system performance. In 2014 IEEE PES T\&D Conference and Exposition. 2014: 1-5.

[16] Eldery MA, El-Saadany EF, Salama MM. Effect of distributed generator on the allocation DSTATCOM in distribution network. In 2005. IEEE Power Engineering Society General Meeting. 2005: 2360-2364. 
[17] Moghbel M, Masoum MA, Deilami S. Optimal placement and sizing of multiple STATCOM in distribution system to improve voltage profile. In 2016 Australasian Universities Power Engineering Conference (AUPEC). 2016: 1-5.

[18] Tiwari D, Ghatak SR. Performance enhancement of distribution system using optimal allocation of distributed generation \& DSTATCOM. In 2017 International Conference on Innovative Mechanisms for Industry Applications (ICIMIA). 2017: 533-538.

[19] Pal K, kumar Panigrahi B, Mohapatra S, Mohapatra A. Impact of STATCOM on voltage profile in a DG penetrated grid connected system. In 2017 International Conference on Circuit, Power and Computing Technologies (ICCPCT). 2017: 1-5. 